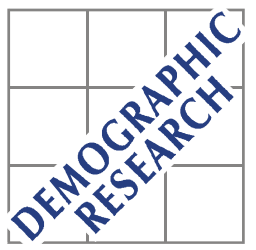

Demographic Research a free, expedited, online journal of peer-reviewed research and commentary in the population sciences published by the Max Planck Institute for Demographic Research Konrad-Zuse Str. 1, D-18057 Rostock · GERMANY www.demographic-research.org

DEMOGRAPHIC RESEARCH

VOLUME 10, ARTICLE 5, PAGES 121-142

PUBLISHED 15 APRIL 2004

www.demographic-research.org/Volumes/Vol10/5/

DOI: $10.4054 /$ DemRes.2004.10.5

Research Article

\title{
The Impact of Parents' and Spouses' Education on Divorce Rates in Norway
}

\section{Torkild Hovde Lyngstad}

(C) 2004 Max-Planck-Gesellschaft. 


\section{Table of Contents}

1 Introduction 122

2 Theoretical Arguments 123

$2.1 \quad$ Educational attainment and divorce 124

$2.2 \quad$ Parental education and divorce 125

2.3 Educational homogamy and divorce risk 126

$\begin{array}{lll}2.4 & \text { Further education and divorce } & 127\end{array}$

$3 \quad$ Data and Methods $\quad 128$

$4 \quad$ Results and Discussion $\quad 129$

4.1 Large differentials in divorce risk by education 134

4.2 A positive effect from parental education 135

4.3 Further education leads to an elevated risk of 136

$\begin{array}{lll}4.4 & \text { Control variables } & 137\end{array}$

$\begin{array}{lll}5 & \text { Conclusion } & 138\end{array}$

6 Acknowledgements 139

$\begin{array}{ll}\text { References } & 140\end{array}$ 


\title{
The Impact of Parents' and Spouses' Education on Divorce Rates in Norway
}

\author{
Torkild Hovde Lyngstad ${ }^{1}$
}

\begin{abstract}
According to both economic and sociological theory, a couple's divorce rate may be influenced by their own educational attainment, that of their parents, and whether they have taken further education after marriage, although predictions are ambiguous. However, these three variables have never been included simultaneously and few studies have included both partners' characteristics. A discrete-time hazard model based on register and census data on 54178 Norwegian first marriages started 1980-1999 reveals a very strong negative educational gradient in divorce risk and no particularly harmful influence of heterogamy. Parent's education exerts a small positive effect, however. Among couples with the same current level of education, those who have taken education after entry into marriage display the highest divorce rate.
\end{abstract}

1 Division for Social and Demographic Research, Statistics Norway, PO Box 8131 Dep, 0033 Oslo,

Noway.E-mail: thl@ssb.no 


\section{Introduction}

Theoretical contributions on the impact of the spouses' educational attainments and parental educations on the divorce rate usually assume that any gradients in divorce risk are determined jointly by both spouses' characteristics. However, empirical studies of divorce determinants have often been based on data that include the educational attainment of one spouse only (e.g. de Rose 1992; Hoem 1997). Besides, some authors have had access to data on both husband's and wife's education but not considered the combined effects (e.g. Bracher et al 1993; Ono 1998; Jalovaara 2001).

Of the relatively few studies that have addressed the joint impact of spouses' education, results reported for Nordic countries point towards negative effects of education on divorce risk (Kravdal and Noack 1989; Hansen 1995; Jalovaara 2003), but the studies of other countries are less conclusive: Poortman and Kalmijn (2002) found positive effects of the wife's education on divorce risk in the Netherlands. The most important conclusion of Bumpass and Sweet (1972) was that educational heterogamy had no positive influence on divorce risk. Tzeng and Mare (1995) found negative effects of the couple's education in the U.S.

Other studies have dealt with the importance of social background, measured either as the social class or education of parents (e.g. Bumpass et al 1991; Hoem and Hoem 1992; Bracher et al 1993; Hansen 1995; Berrington and Diamond 1999; Jalovaara 2001). The bulk of the evidence suggests that individuals from "bourgeois" backgrounds, or who have well-educated parents, have slightly higher divorce rates than others (but see Bumpass et al 1991 for a counter-example). The impact of schooling after entry into marriage has also attracted some attention. For example, Tzeng and Mare (1995) found that increases in husband's education during marriage raised divorce risk, whereas there was no such effect for wives. However, no studies have included this variable as well as spouses' education (as a combined variable) and parents' education (also as a combined variable) in the same model. Given the potentially large correlation between them, it might well be that such a model gives estimates that are substantially different from those obtained in simpler models.

Moreover, educational attainment is a variable that is thought to affect the economic organization of the household but also grant individuals non-economic rewards. These effects might work in opposite directions. In this paper, this theoretical ambiguity is taken into account by estimating effects of education net of both spouses' income, leaving us with estimates of the non-economic effect of education on divorce risk. 


\section{Theoretical Arguments}

The theoretical framework used in this paper is the general economic-demographic approach to family dynamics. It is built on a broad concept of the costs and utility of the available modes of family organization. The framework is similar to rational choice theory, which many sociologists and demographers employ in their theorizing. The basic assumption is that each individual tries to maximize utility by entering or leaving unions (England and Farkas 1986; Becker 1991).

For individuals to marry, entering a marriage must yield certain benefits. These benefits are not to be understood here as only being of an economic nature. Rather, benefits as emotional support and companionship are all included in the utility from the union, along with economic benefits.

To locate potential mates, each individual searches in a market of potential marriage partners for an optimal match. As this search entails certain costs, the individual must weigh the expected marginal gain from searching longer against the costs of further search. The marginal increase in utility from finding a better partner is dependent on structural constraints such as the age and sex structure and other characteristics of the population in which the search is made (Fossett and Kiecolt 1991; South and Lloyd 1995).

The total benefits of a union with the available partner, net of the costs of being married determine the spouses' gain from marriage. After internal negotiations on the division of the gain from marriage, both persons must have no available alternative that would yield a higher expected gain. It is important to note that the gain from marriage is determined for the couple as a unit, and not individually for the two spouses and then pooled. The spouses' individual shares of the gain are determined through bargaining between the two spouses.

If the gain from marriage drops so that any spouse's share of the gain falls below the expected utility from being single, or the expected utility from a remarriage with an alternative partner, he or she will consider divorce. These considerations must include search costs and costs associated with the divorce itself (such as establishing a new household, any stigma connected to marital disruption, or the breakdown of common social networks). If the marginal gain in utility from a break-up outweighs the costs, the person will file for divorce.

Many factors are thought to partly determine the gain from marriage. Examples include children, housing, knowledge about each others preferences and habits, social networks, any wealth the spouses may have acquired, their beliefs and worldviews, and so on.

Becker and colleagues argue that the degree to which the spouses' specialize in the production of market goods, i.e. labor force participation, or domestic goods, i.e. 
housekeeping and childrearing, is positively correlated with the gain from marriage. However, this specialization model was outlined during a period of time when most women did not take part in the labor force. During the last few decades, wives' participation rates have soared in concert with policy reforms and attitudinal changes towards gender equality. The specialization model is therefore likely to be of much less relevance today than when it was first proposed, and particularly so in the Norwegian context given the high rates of female labor force participation and university enrolment. Oppenheimer (1994) has suggested that a "pooling-of-resources"-model in which the gain from marriage is highest when both spouses contribute economically to the household is more appropriate for the current situation than Becker's specialization model.

Which of these models that best portray the economic organization of Norwegian marriages in the period 1980-1999 is an empirical question, but is left for future analyses. The economic variables serve here as control variables, used to remove the contribution of economic variables from the effect of educational attainment on divorce risk.

\subsection{Educational attainment and divorce}

In Becker's theory of the union formation process it is argued that highly educated men tend to marry highly educated women and less educated men tend to marry less educated women (Becker 1977, 1991). Becker sees this pattern as the result of a competition for the partners with the highest education, and assumes that people regards individuals that hold high educations as superior to those who hold low educations. Hence, a couple where at least one spouse has a higher education will enjoy a higher gain from marriage than a couple where none of the spouses have higher educations. Moreover, it is also argued that there is a premium on the gain from marriage for couples where both have long educations.

The clear-cut picture of the impact educational attainment has on divorce risk can, however, be confused by another effect on divorce risk working through economic potential. A wife with a higher education has better labor market prospects and earnings potential than a wife with a lower education. In marriages where the wife has a long education, her better economic prospects reduce the relative benefits from specializing and will help her gain economic independence. The degree of specialization will be lower in couples where the wife has a comparatively high education, and hence is there a positive effect of wives' education on the divorce risk working through their economic potential. 
Thus, there might be two opposing effects from education on the risk of divorce: One being a direct (in the sense that it does not operate through economic factors) effect of education, increasing the gain from marriage, and one being an effect working indirectly through reduced specialization, potentially decreasing the gain from marriage. Becker et al (1977) admit that the net effect of education on divorce risk is theoretically ambiguous if the specialization model is correct.

If one can filter out the effect of potential earnings, and be left with the noneconomic effect of education that raises the gain from marriage, the effect of educational attainment on divorce risk should be negative. The relative divorce risks predicted for the various combinations of the spouses' educational attainment is illustrated in figure 1 .

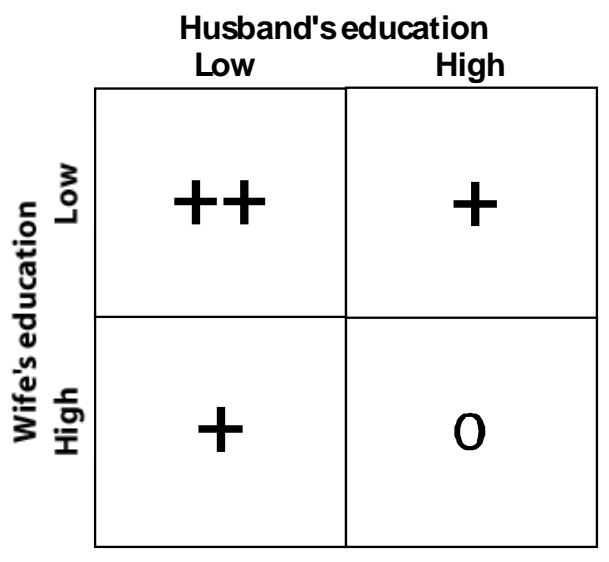

Figure 1: Educational gradients in divorce risk predicted by the economicdemographic approach

\subsection{Parental education and divorce}

Becker et al (1977) argue that there should be positive assortative mating on all variables that are not good substitutes for, and in effect strong correlates of, earning power. They treat social background similarly to how they deal with wealth, physical attractiveness, and, apart from the complications related to economic potential, educational attainment: They assume that social background is positively correlated with the gain from marriage, and therefore that having a high social background reduces divorce risk. 
In this paper, social background is measured by the education of the spouses' parents. The predictions of divorce risk gradients in a variable that is positively sorted corresponds to the ones shown in figure 1 for the direct effect of education in divorce risk: Compared to a couple where none have highly educated parents, the divorce risk is lower if at least one of the spouses have parents with high educations and lowest if both of the spouses have parents with high education.

From the existing empirical studies one may find alternative understandings of the role social origin can play in marital disruption: Hoem and Hoem (1992) suggested that social background, in their case measured as the father's occupational class, is positively correlated with divorce risk due to some socio-cultural factor found in the upper and middle classes that makes divorce easier in some way (i.e. reducing the costs of divorce). They do not elaborate on the nature of this factor, however.

Two other possible explanations are related to getting economic support from the spouses' parents: Well-educated parents are likely to be better off financially and more able to support their children through rough times. But, the prediction on divorce risk is ambiguous: The parents could transfer money to their offspring in order to either stay married in times where the couple's resources is strained or they could facilitate a divorce financially when the spouse's own income is not sufficient to establish a new household.

\subsection{Educational homogamy and divorce risk}

Becker's micro-economic approach views the formation of assortative mating patterns as the result of a competition for persons with the highest socioeconomic status, education, wealth, et cetera.

However, there is another plausible view of how such patterns are formed. This competing view suggests that the spouses desire similarity in characteristics such as educational attainment, and not necessarily a partner with the highest education or social background. Thus, persons may value marriages with individuals with the same educational attainment as themselves higher than marriages with a person that has the highest possible educational attainment.

Implying that there is some kind of frustration related to not being similar in characteristics such as educational attainment or social background, some researchers have also predicted that homogamy in education and social background should promote marital stability (Lewis and Spanier 1979). The pattern of relative divorce risks predicted by this view is shown in figure 2 . 


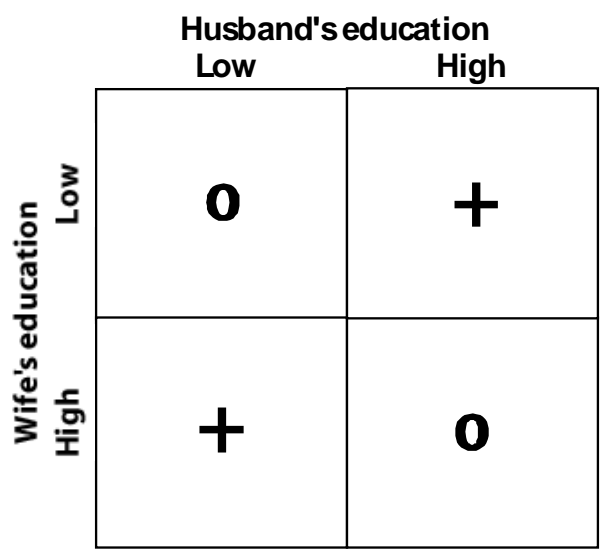

Figure 2: $\quad$ Educational gradients in divorce risk predicted by the homogamyoriented approach

\subsection{Further education and divorce}

An increase in education would affect the gain from marriage and cause a redistribution of the gain between the spouses. Either spouse's further education during marriage may therefore have an independent effect on divorce risk.

Although the higher qualification might make a positive contribution to the marriage, the change in itself might be a disruptive factor (Tzeng and Mare 1995). Results from qualitative studies corroborate these ideas and suggest that such effects may be particularly strong for wives' further education (Hochschild 1989; Moxnes 1990).

The effect of obtaining further education can be identified if one controls for the newly obtained level of education, which is done in the present study. One could also search for interaction effects between current educational attainment and further education, i.e. the effect of moving from heterogamy to homogamy in educational attainment (or vice versa), but that problem is very complex and is left to a separate study. 


\section{Data and Methods}

The data set used in this study includes the date of marriage and divorce (if any), date of any spousal deaths, the spouses' previous marital status (used to select first order marriages), time series from 1980 to 1999 of each spouse's annual income, educational attainment, and educational activity, the educational level of each spouse's parents, and the individual fertility history of each spouse.

The fertility histories include all childbirths that any of the spouses have experienced up to the end of 2000. Information on each child's date of birth, sex and the PINs of its parents (used to check for premarital childbearing with other persons than the spouse) is included.

The parents' educational levels are mainly taken from the Population Census of 1980 , but if it is missing from this census, information from the 1970 census is used wherever possible.

There is no indicator of average working hours. A measure of hourly wage would be a better indicator of the person's true economic potential than annual income, but is not available.

The data set is, due to restrictions from the Data Inspectorate, limited to marriages where the husband is born in 1940, 1945, 1950, 1955, 1960, 1965, 1970, 1975, or 1980. Only first marriages for both partners are included due to the special selection processes that are at work in second and higher-order unions. To avoid any confounding factors related to ethnic intermarriage, only couples where both spouses are Norwegian-born are selected for analysis. After the selection criteria are applied, the final data set consists of 54178 marriages.

I have chosen to employ discrete-time hazard regression models in the analysis (Allison 1984, Blossfeld and Rohwer 1995). The dependent variable is the conditional probability (measured in log-odds) of a couple's divorce in year $t$, given that the couple was at risk at the start of year $t$.

Formal divorce is taken as the time of dissolution, although the time of separation could be a more appropriate measure for the break-up. The rationale for this is that divorce is an irreversible event and a substantial number of separated couples reconcile without reporting to the population register when they move back together.

All independent variables are categorical covariates at either nominal or ordinal response levels. The time-dependent variables are lagged two calendar years. This is done because the Norwegian authorities, to grant a no-fault divorce, require the couple to be separated for at least one year prior to the formal divorce. Moreover, the explanatory variables are measured at an accuracy of one year. This requires a lag of one year to avoid any anticipatory regressors. For the same reason, the temporal unit is calendar years. 
Each spouse's educational attainment is coded as a categorical variable by grouping a standard classification of 9 education levels into a three-level scale: primary education, secondary education (mostly three years of either vocational training or academic preparatory courses), and tertiary education. These variables are timedependent, and therefore updated for every subsequent marriage-year.

Similarly to Jalovaara (2003), I study the combination of spouses' educational attainment. Cross-classifying the spouses' educational levels gives a $3 \times 3$ matrix of combinations. The middle cell in the matrix is arbitrarily chosen as a baseline category. Another $2 \times 2$ matrix variable measures if any increases have occurred in the spouses' educational attainment during their marriage.

Parental education is measured for each spouse by the highest level of education recorded for either the spouse's father or the spouse's mother. Having at least one parent with secondary schooling is regarded as a high level of parental education. This information is used to compute a $2 \times 2$ matrix variable of combinations of parental education.

Unfortunately, there is no data on the economic resources of the spouses' parents. Lack of control for parental economic resources may confound the relationship between parental education and divorce risk, and make it harder to understand the nature of any gradients in divorce risk by parental education.

It is likely that the couples included in this study are selected into marriage from cohabitation by various socio-economic variables. Kravdal (1999) reports a positive effect of educational attainment on the transition rate from cohabitation into first marriage. This may indicate that cohabiting couples with shorter educations that marry, rather than remain cohabitants or split up, may be a (strongly) selected group of firmer unions that are less divorce-prone. If that argument is valid, the results presented here will be underestimating lesser-educated couples' risk of union dissolution.

\section{Results and discussion}

The final data set contains 508470 marriage-years, with a total of 8086 divorces. Table 1 shows the frequency distributions of marriage-years for all the variables included in the model. Note that the classifications of the variables age at marriage and income differ for husband and wife.

The only variable where missing values are likely to bias the results is the indicator of parental education. To remedy this, a separate category indicating a missing value was constructed and added to the model along with the categorical variable measuring the spouses' parental education. The estimates for the dummy variable do not indicate 
Demographic Research - Volume 10, Article 5

Table 1: $\quad$ Distribution of marriage-years over analysis variables

\begin{tabular}{|c|c|}
\hline Variable/Category & Per cent \\
\hline \multicolumn{2}{|l|}{ Duration } \\
\hline 0 & 7.7 \\
\hline 1 & 8.6 \\
\hline 2 & 9.3 \\
\hline 3 & 8.6 \\
\hline 4 & 8.0 \\
\hline $5--7$ & 20.8 \\
\hline 8--10 & 16.0 \\
\hline $11--14$ & 14.0 \\
\hline $15+$ & 7.0 \\
\hline \multirow{2}{*}{\multicolumn{2}{|c|}{$\begin{array}{l}\text { Educational attainment } \\
\text { (wife's level/husband's level) }\end{array}$}} \\
\hline & \\
\hline Low/Low & 2.5 \\
\hline Low/Medium & 6.4 \\
\hline Low/High & 0.2 \\
\hline Medium/Low & 8.8 \\
\hline Medium/Medium & 58.2 \\
\hline Medium/High & 8.0 \\
\hline High/Low & 0.4 \\
\hline High/Medium & 7.9 \\
\hline High/High & 7.6 \\
\hline \multicolumn{2}{|l|}{ Husband's age at marriage } \\
\hline--24 & 27.3 \\
\hline $25--29$ & 48.2 \\
\hline $30--34$ & 18.8 \\
\hline $35+$ & 5.7 \\
\hline \multicolumn{2}{|l|}{ Wife's age at marriage } \\
\hline--19 & 5.7 \\
\hline $20--24$ & 48.8 \\
\hline $25--29$ & 34.6 \\
\hline $30--34$ & 8.7 \\
\hline $35+$ & 2.2 \\
\hline \multicolumn{2}{|c|}{ Children with others before marriage } \\
\hline None & 92.8 \\
\hline Husband has & 2.7 \\
\hline Wife has & 4.0 \\
\hline Both have & 0.5 \\
\hline \multicolumn{2}{|c|}{ Premarital childbearing (with current spouse) } \\
\hline No & 60.7 \\
\hline Yes & 39.3 \\
\hline \multicolumn{2}{|l|}{ Age homogamy } \\
\hline Wife $4+$ years older & 2.5 \\
\hline Age homogamous & 65.8 \\
\hline Husband $4+$ years older & 31.7 \\
\hline
\end{tabular}


Demographic Research - Volume 10, Article 5

Table 1 (cont.): Distribution of marriage-years over analysis variables

\begin{tabular}{lc}
\hline Variable/Category & Per cent \\
\hline Husband's income & \\
OK--50K & 12.4 \\
51K--100K & 46.3 \\
101K--150K & 31.2 \\
151K--200K & 7.0 \\
201K+ & 3.1 \\
Wife's income & \\
OK--25K & 27.5 \\
26K--50K & 23.0 \\
51K-100K & 43.6 \\
101K-150K & 5.2 \\
151K+ & 0.7 \\
Parental education & \\
Both low & 49.4 \\
Husband high & 16.7 \\
Wife high & 18.7 \\
Both high & 13.9 \\
Missing data & 1.3 \\
Further education during marriage & \\
None & 89.4 \\
Husband completed further ed. & 4.2 \\
Wife completed further ed. & 4.9 \\
Both completed further ed. & 1.5 \\
Current educational activity & \\
None enrolled & 89.6 \\
Husband enrolled & 3.7 \\
Wife enrolled & 5.4 \\
Both enrolled & 1.4 \\
Number and age of Children & 2.4 \\
No children & 6.2 \\
1, aged 0 years & 5.3 \\
1, aged 1-6 years & 2.7 \\
1, aged 7+ years & 8.9 \\
2, aged 0 years & 1.4 \\
2, youngest aged 1-6 years & \\
2, youngest aged 7+ years & \\
3, youngest aged 0 years & \\
3, youngest aged 1-6 years & \\
3, youngest aged 7+ years & \\
\hline & \\
&
\end{tabular}

http://www.demographic-research.org 
Demographic Research - Volume 10, Article 5

Table 2. Divorce risk estimates for all variables from the discrete-time hazard regression model. Odds ratios

\begin{tabular}{|c|c|c|c|}
\hline Variable/Category & Odds ratio & Lower C.L. & Upper C.L. \\
\hline \multicolumn{4}{|l|}{ Duration of marriage } \\
\hline 0 & 0.00 & 0.00 & 0.01 \\
\hline 1 & 0.03 & 0.02 & 0.04 \\
\hline 2 & 0.26 & 0.23 & 0.30 \\
\hline 3 & 0.62 & 0.56 & 0.69 \\
\hline 4 & 0.91 & 0.83 & 0.99 \\
\hline $5-7$ & 1.00 & . & \\
\hline $8-10$ & 0.96 & 0.89 & 1.03 \\
\hline $11-14$ & 0.81 & 0.74 & 0.89 \\
\hline $15+$ & 0.62 & 0.55 & 0.71 \\
\hline \multicolumn{4}{|l|}{ Age difference } \\
\hline Wife $4+$ yrs & 1.44 & 1.22 & 1.69 \\
\hline Homogamous & 1.00 & . & . \\
\hline Husband $4+\mathrm{yrs}$ & 1.21 & 1.13 & 1.29 \\
\hline \multicolumn{4}{|c|}{ Husband's age at marriage } \\
\hline--24 & 1.25 & 1.17 & 1.33 \\
\hline $25-29$ & 1.00 & . & . \\
\hline $30-34$ & 0.86 & 0.79 & 0.93 \\
\hline $35+$ & 0.74 & 0.63 & 0.86 \\
\hline \multicolumn{4}{|l|}{ Wife's age at marriage } \\
\hline-19 & 1.97 & 1.77 & 2.21 \\
\hline $20-24$ & 1.41 & 1.31 & 1.51 \\
\hline $25--29$ & 1.00 & . & \\
\hline $30-34$ & 0.68 & 0.60 & 0.78 \\
\hline $35+$ & 0.44 & 0.33 & 0.58 \\
\hline \multicolumn{4}{|c|}{ Children with others before marriage } \\
\hline None & 1.00 & . & . \\
\hline Both & 2.06 & 1.61 & 2.62 \\
\hline Wife & 1.83 & 1.66 & 2.03 \\
\hline Husband & 2.21 & 1.99 & 2.46 \\
\hline \multicolumn{4}{|c|}{ Premarital childbearing } \\
\hline No & 1.00 & . & . \\
\hline Yes & 1.62 & 1.53 & 1.72 \\
\hline \multicolumn{4}{|c|}{ Number and age of children } \\
\hline No children & 1.00 & . & \\
\hline 1,0 years & 0.30 & 0.26 & 0.36 \\
\hline $1,1-6 \mathrm{yrs}$ & 0.76 & 0.70 & 0.83 \\
\hline $1,7+y r s$ & 0.94 & 0.81 & 1.08 \\
\hline $2,0 \mathrm{yrs}$ & 0.24 & 0.20 & 0.28 \\
\hline $2,1-6 \mathrm{yrs}$ & 0.55 & 0.50 & 0.61 \\
\hline $2,7+y r s$ & 0.65 & 0.56 & 0.75 \\
\hline $3+, 0 \mathrm{yrs}$ & 0.15 & 0.11 & 0.19 \\
\hline $3+, 1-6 \mathrm{yrs}$ & 0.42 & 0.37 & 0.48 \\
\hline $3+, 7+y r s$ & 0.51 & 0.40 & 0.64 \\
\hline
\end{tabular}


Demographic Research - Volume 10, Article 5

Table 2 (cont.): Divorce risk estimates for all variables from the discrete-time hazard regression model. Odds ratios

\begin{tabular}{|c|c|c|c|}
\hline Variable/Category & Odds ratio & Lower C.L. & Upper C.L. \\
\hline \multicolumn{4}{|l|}{ Educational activity } \\
\hline None enrolled & 1.00 & . & . \\
\hline Wife enrolled & 1.87 & 1.72 & 2.05 \\
\hline Husband enrolled & 1.07 & 0.94 & 1.21 \\
\hline Both enrolled & 1.11 & 0.88 & 1.39 \\
\hline \multicolumn{4}{|l|}{ Husband's income } \\
\hline $0 \mathrm{~K}-50 \mathrm{~K}$ & 1.47 & 1.36 & 1.59 \\
\hline $51 \mathrm{~K}-100 \mathrm{~K}$ & 1.08 & 1.02 & 1.14 \\
\hline $101 \mathrm{~K}-150 \mathrm{~K}$ & 1.00 & . & . \\
\hline $151 \mathrm{~K}-200 \mathrm{~K}$ & 1.00 & 0.91 & 1.12 \\
\hline $201 K_{+}$ & 1.11 & 0.96 & 1.29 \\
\hline \multicolumn{4}{|l|}{ Wife's income } \\
\hline $0 \mathrm{~K}-25 \mathrm{~K}$ & 0.43 & 0.38 & 0.48 \\
\hline $26 \mathrm{~K}-50 \mathrm{~K}$ & 0.48 & 0.43 & 0.54 \\
\hline $51 \mathrm{~K}-100 \mathrm{~K}$ & 0.60 & 0.55 & 0.66 \\
\hline $101 \mathrm{~K}-150 \mathrm{~K}$ & 1.00 & . & . \\
\hline $151 K_{+}$ & 1.13 & 0.88 & 1.45 \\
\hline \multicolumn{4}{|l|}{ Education level (wife/husband) } \\
\hline Low/Low & 1.84 & 1.64 & 2.06 \\
\hline Low/Medium & 1.55 & 1.43 & 1.68 \\
\hline Low/High & 1.26 & 0.83 & 1.92 \\
\hline Medium/Low & 1.31 & 1.22 & 1.42 \\
\hline Medium/Medium & 1.00 & . & . \\
\hline Medium/High & 0.69 & 0.62 & 0.78 \\
\hline High/Low & 0.85 & 0.59 & 1.21 \\
\hline High/Medium & 0.53 & 0.47 & 0.60 \\
\hline High/High & 0.42 & 0.36 & 0.48 \\
\hline \multicolumn{4}{|l|}{ Parental education (wife/husband) } \\
\hline Low/Low & 1.00 & . & . \\
\hline Low/High & 1.19 & 1.09 & 1.23 \\
\hline High/Low & 1.16 & 1.11 & 1.27 \\
\hline High/High & 1.45 & 1.34 & 1.56 \\
\hline \multicolumn{4}{|l|}{ Further education (wife/husband) } \\
\hline None & 1.00 & . & . \\
\hline Yes/No & 1.43 & 1.27 & 1.66 \\
\hline No/Yes & 1.23 & 1.09 & 1.38 \\
\hline Yes/Yes & 1.41 & 1.13 & 1.76 \\
\hline-2 log likelihood (no covariates) & 83015.38 & & \\
\hline-2 log likelihood (with covariates) & 69375.47 & & \\
\hline
\end{tabular}

http://www.demographic-research.org 
any strong bias related to missing values on the parental education variable. All of the remaining cases where there are missing values on other variables are deleted from the analysis. Table 2 shows the results from the discrete-time hazard regression with all analysis variables included.

\subsection{Large differentials in divorce risk by education}

The results show a general pattern of negative effects of educational attainment on a couple's annual odds of divorce, net of all other covariates. The divorce risk declines with a higher level of the husband's educational attainment and with a high level of the wife's educational attainment. This is in line with the economic-demographic theoretical predictions, even when the effect of wives' increased economic potential due to higher education is taken into account.

A negative relationship between educational attainment and divorce risk also accords with most of the earlier research on this topic from the Nordic countries. The differentials found in the other Nordic studies have, however, been smaller in magnitude (Kravdal and Noack 1989, Hoem 1997, Jalovaara 2001, 2003). From other countries, results have indicated a positive (or close to zero) effect of education on divorce. In Australia, Bracher et al (1993), found no relation between education and divorce. Ono (1998) and Poortman and Kalmijn (2002) found, for the United States and the Netherlands respectively, positive effects of educational attainment on divorce risk.

It is unclear why education matters more for divorce risk in Norway than in many other countries. Some additional control variables that are likely to be correlated with educational attainment are included, in particular parental education. This may give higher point estimates for the education gradients.

Moreover, the Finnish study by Jalovaara (2003) had only left-truncated marital histories available, and may therefore be underestimating education effects on divorce risk due to attrition (Guo 1993). Such underestimation can be particularly strong for education, as Jalovaara (2002) also shows that the education effects are at their strongest during early marital durations.

The effect of the wife's education level seems to be stronger than the corresponding effect of the husband's education. When economic potential is controlled for, one should expect that effects of educational attainment show a symmetric pattern as the one found by Jalovaara (2003). The reason for the asymmetric pattern of gradients found in this study can be explained by the higher part-time employment rates among Norwegian wives compared with Finnish wives. Wives working part-time will have lower incomes than those working full-time, net of education differences in wages. 
This means that economic potential of Norwegian women is not fully captured by the income variables, and an asymmetric pattern of gradients is observed.

\subsection{A positive effect from parental education}

In the literature, there is no conclusive evidence on the effect of parental education, social class background, or homogamy in such variables on divorce risk.

Bumpass et al (1991) found a weak curvilinear effect of mother's education on divorce risk in the United States. A British study has found that having a lower-class background reduces divorce risk (Berrington and Diamond 1999). In the results of the present analysis, couples with well-educated parents run significantly higher risks of divorce net of all other covariates. There are positive effects of the same magnitude of both spouses' parental education on the couple's divorce risk. While Hansen (1995) reported lower divorce risks for couples that are homogamous with respect to social class, these results provide no indication of any protective effect for couples that are homogamous with respect to parental education. On the contrary, couples where both spouses have educated parents run an added risk of divorce.

This finding may be attributed to several different explanations. Hoem and Hoem (1992) suggested that the reason for an elevated risk of divorce for couples with educated parents could be found in the "bourgeois culture" among the highly educated.

An alternative explanation regards the economic resources of the spouse's parents, possibly causing an "independence effect". If a spouse has parents that are willing to economically support their offspring after divorce, the spouse might look upon the marital disruption process with fewer concerns. Couples with well-off parents may also get financial assistance in rough times that could reduce marital discord and consequently the divorce risk, but as the pattern show positive gradients by parental education this mechanism cannot dominate the process.

A final explanation is connected to parental divorce, which has been shown to influence various aspects of individuals' demographic behavior including divorce risk (Cherlin et al 1995; Kiernan and Cherlin 1999; Berrington and Diamond 1999). The children of early divorcees will have more information on how the divorce process can be handled, and may consequently view marital disruption differently than spouses with parents that are still married. In order for the relationship between parental education and divorce risk to be confounded by parental divorce, the effect of the spouses' own education on divorce risk must have been positive for the marriage cohorts to which the parents of the couples in this study belongs.

Most of the parents of the couples included in this study were born throughout the 1930s. When they married, it was both socially and economically costly to divorce. 
After a divorce one could experience sanctions from peers and society, and a social support system for single parents was yet to be established. Therefore, the persons who divorced at that time may have been some kind of innovators with more cultural resources to withstand stigma attached to divorce and to cope with the economic strains a marital break-up induces on divorcees. As such resources often are correlated with educational attainment, this would lead to a positive correlation between the education level and the divorce rate for the parents of the couples in the present study.

The above argument implies that the effects of education on divorce risk, throughout the second demographic transition, must have changed from being positive for the parent generation into being negative for the next generation. Blossfeld et al (1995) argue that there is a bell-shaped relationship between divorce risk and educational attainment across time. Norway should, according to their hypothesis, be at the very right end of the bell-shaped curve as wives' educational attainment is comparatively high and social acceptance of divorce and "alternative" family forms is strong.

A country like Italy, with lower female employment rates and a lesser acceptance of cohabitation and marital dissolution, should be at an earlier stage of the second demographic transition. The relationship between wives' education and divorce risk should therefore be negative in Italy, as found by for example de Rose (1992).

It is not extremely unlikely that such changes have taken place throughout the last decades, but it would be contradictory with both earlier research on education gradients in divorce risk for the 1968 marriage cohort (Kravdal and Noack 1989) and with recent results from the United States reporting that divorce risk factors show a large degree of stability across cohorts (Teachman 2002).

As limitations in the data make it impossible to fully understand the mechanisms behind the positive effect of parental education on divorce risk, this problem should be explored in greater detail using data on the demographic characteristics and economic resources of the spouses' parents.

\subsection{Further education leads to an elevated risk of divorce}

Tzeng and Mare (1995) found that changes in both the wife's income and her educational attainment slightly increased dissolution risk. However, they found no effect of increases in the husband's educational attainment on divorce risk.

This analysis finds that further education for either spouse raises divorce risk. Most pronounced are, however, the effects associated with an increase in her level of education after marriage. But, even couples where only the husband has completed further education during marriage run a risk of divorce. 
A heightened risk of divorce after an increase in education may also be an artifact of anticipation: A spouse in a low-quality marriage may be considering a break-up and therefore also preparing for it by obtaining further education.

\subsection{Control variables}

Age at marriage is one of the best-documented determinants of divorce (Booth and Edwards 1985, South 1995). For both spouses, marrying young heightens their risk of divorcing. The effects found here are particularly strong for marriages with teenage brides. Age heterogamy raises divorce risk with 21 per cent when the husband is the oldest spouse, and 44 per cent when the wife is the oldest spouse.

Another strong correlate of divorce is the couple's parity and the age of their youngest child (Waite and Lillard 1991, Andersson 1997). In the present analysis, the effects from having an infant child reduce the divorce risk to a small fraction of that of the baseline group consisting of couples without children. As the youngest child grows older, divorce risk increases.

Earlier research has documented the importance of premarital childbearing for divorce risk (Kravdal 1988, Tzeng and Mare 1995, Liu 2002). Two variables measuring this were included in the model: One measures whether the couple initiated their own fertility career within wedlock or not, and the other variable measures, for each spouse, whether the spouse has had any children with someone else than the current partner before marriage.

The results from this analysis indicate substantially higher divorce risks for persons that initiate childbearing with someone else than their first marital partner. If the husband has at least one child with a different woman than his wife before marriage, the risk of divorce is 2.2 times higher than if he has no children with others before the marriage. For the wife, the corresponding odds ratio is 1.8. If both have had children with others before they married, the odds ratio is 2.0. The couples that have had a birth with someone else than their first marital partner, most likely in an earlier informal union, could hold more liberal values with respect to family life in general.

Kravdal (1988) reported a doubling of divorce risk for Norwegian couples that initiated childbearing outside of marriage. Due to the rise in cohabitation and out-ofwedlock fertility during the 1980s and 1990s, one would expect that this effect is now lower. The results of this study indicate a relative divorce risk 1.6 times the baseline risk for such couples.

For couples where the wife was enrolled, the odds of divorce were 1.9 times higher than in the baseline group. The enrolment effect might be explained by several factors: The poorer economic standing of student spouses, the possibly differing lifestyles 
between studying spouses and employed spouses, or there might be a surplus of potential mates in the student population increasing the likelihood of encountering a partner superior to the current. This explanation requires, however, more information of the student population.

However, if the divorce is anticipated, a spouse will be more likely to study in order to prepare for the potential economical challenges that may follow. Although the time lag between divorce and the explanatory variables is two calendar years, preparations for single life might start even earlier.

Income effects conform to the specialization model, showing a negative effect on the divorce rate of the husband's income and a positive effect on the divorce rate from the wife's income.

\section{Conclusion}

By combining the characteristics of both marriage partners as theoretical contributions imply, this paper is the first to simultaneously study the effect of spouses' educational attainments, their parents' educations and completion of further education during marriage.

Education effects on divorce are strongly negative in Norway. The results showed no protective effect of educational homogamy. The magnitude of the divorce risk differentials presented in this study is substantially larger than in any similar study on this topic from the Nordic countries (e.g. Kravdal and Noack 1989; Hoem 1997; Jalovaara 2001, 2002, 2003). A couple where both spouses have low levels of education run a risk that is more than four-fold in magnitude compared to couples where both have higher educations.

Parental education exerts a positive influence on divorce risk for both spouses. Moreover, there is an added risk of divorce for couples where both partners have high parental education levels. These findings lend support to a view suggesting that transmission of liberal attitudes and more liberal norms towards marital disruption can be a result of socialization in highly educated families, although this should be explored in greater detail in future studies.

The third finding of this study is that if at least one spouse obtains further education after marrying, the risk of divorce increases and does so independently of the current level of education. Further education may be a stressor in marital life itself, but the relationship might also be due to reverse causation: Anticipating divorce in a lowquality marriage may provide an incentive to obtain further education as a preparation for single life. 


\section{Acknowledgements}

The Research Council of Norway supported this study through grants \#137156/530 and \#149008/730. Drafts of this paper have been presented at an internal seminar in Statistics Norway, a meeting of the European Network for the Sociological and Demographic study of Divorce in Florence, Italy 14.-15. November 2002 and the ISA Research Committee on Social Stratification and Mobility meeting in Tokyo, Japan 1.3. March 2003. The author wishes to thank Øystein Kravdal, Marika Jalovaara, participants at the above-mentioned seminars, colleagues at Statistics Norway, and Demographic Research's three anonymous referees for their very helpful comments. 


\section{References}

Allison, Paul D. 1984. Event history analysis: regression for longitudinal event data. Thousand Oaks, CA: Sage Academic Publishers.

Andersson, Gunnar 1997. "The impact of children on divorce risks of Swedish women", European Journal of Population 13(2): 109--145.

Becker, Gary S., Elizabeth M. Landes, and Robert T. Michael. 1977. "An economic analysis of marital instability", Journal of Political Economy 85: 1141--1188.

Becker, Gary S. 1991. A Treatise on the Family. Cambridge, MA: Harvard University Press.

Berrington, Ann and Ian Diamond. 1999. "Marital disruption among the 1958 British birth cohort: The role of cohabitation", Population Studies 53: 19--38.

Blossfeld, Hans-Peter and Götz Rohwer. 1995. Techniques of Event History Modeling. New Approaches to Causal Analysis. Mahwah, NJ: Lawrence Erlbaum Associates.

Blossfeld, Hans-Peter, Alessandra de Rose, Jan M. Hoem, and Götz Rohwer. 1995. "Education, Modernization, and the Risk of Marriage Disruption in Sweden, West Germany, and Italy" in Karen O. Mason and An-Magritt Jensen (eds.), Gender and Family Change in Industrialized Countries. Oxford: Clarendon Press.

Booth, Alan and J. N. Edwards. 1985. "Age at marriage and marital instability", Journal of Marriage and the Family 47(1): 67--75.

Bracher, Michael, Gigi Santow, S. Philip Morgan, and James Trussel. 1993. "Marriage Dissolution in Australia: Models and Explanations", Population Studies 47(3): 403--425.

Bumpass, Larry L. and James A. Sweet. 1972. "Differentials in marital stability: 1970", American Sociological Review 37: 754--766.

Bumpass, Larry L., Teresa Castro Martin, and James A. Sweet. 1991. "The Impact of Family Background and Early Marital Factors on Marital Disruption", Journal of Family Issues 12(1): 22--42.

Cherlin, Andrew, Kathleen Kiernan, and P. Lindsay Chase-Lansdale. 1995. "Parental divorce in childhood and demographic outcomes in young adulthood", Demography 32(3): 299--318. 
de Rose, Alessandra 1992. "Socio-economic factors and family size as determinants of marital disruption in Italy", European Sociological Review 8(1): 71--92.

England, Paula and George Farkas. 1986. Households, Employment, and Gender. New York: Aldine Publ. Co.

Fossett, M.A. and K.J. Kiecolt. 1991. "A methodological review of the sex ratio: Alternatives for comparative research", Journal of Marriage and the Family 53(4): 941--957.

Guo, Guang. 1993. "Event-history analysis for left-truncated data", Sociological Methodology 23: 217--243.

Hansen, Marianne Nordli 1995. Class and inequality in Norway 1950-1990. Number 95:15 in Reports. Oslo: Institute for Social Research.

Hochschild, Arlie R. 1989. The Second Shift. New York: Avon.

Hoem, Jan M. 1997. "Educational gradients in divorce risk in Sweden in recent decades", Population Studies 51(1): 19--27.

Hoem, Britta and Jan M. Hoem. 1992. "Disruption of marital and non-marital unions in Sweden" in Trussel, J. et al, "Demographic applications of event-history analysis", Oxford: Oxford University Press.

Jalovaara, Marika. 2001. "Socio-economic status and divorce in first marriages in Finland 1991-93", Population Studies 55(2): 119--133.

Jalovaara, Marika. 2002. "Socioeconomic differentials in divorce risk by duration of marriage", Demographic Research 7: 538--564 [Online] Available http://www.demographic-research.org/volumes/vol7/16.

Jalovaara, Marika. 2003. "The joint effects of marriage partners socio-economic positions on divorce risk", Demography 40(1).

Kiernan, Kathleen and Andrew Cherlin. 1999. "Parental divorce and partnership dissolution: Evidence from a British cohort study", Population Studies 53(1): 39-48 .

Kravdal, Øystein. 1988. "The impact of first-birth timing on divorce: New evidence from a longitudinal analysis based on the central population register of Norway", European Journal of Population 4: 247--263.

Kravdal, Øystein. 1999. "Does marriage require a stronger economic underpinning than informal cohabitation?", Population Studies 53(1): 63--80. 
Kravdal, Øystein and Turid Noack. 1989. "Like marries like -- the safest choice?", Scandinavian Population Studies 9: 243--258.

Lewis, R. A. and G. B. Spanier 1979. "Theorizing about the quality and stability of marriage" in W. R. Burr, R. Hill, F. I. Nye, and I. L. Reiss (eds.), Contemporary theories of the family, Volume 1. New York: The Free Press.

Liu, Guiping. 2002. "How premarital children and childbearing in current marriage influence divorce of Swedish women in their first marriages", Demographic Research 7(10): 390--405.

Moxnes, Kari. 1990. Kjernesprengning i familien? Oslo: Scandinavian University Press.

Oppenheimer, Valerie Kincade. 1994. "Women's rising employment and the future of the family in industrialized countries", Population and Development Review 20(4):293--342.

Poortman, Anne-Rigt and Matthijs Kalmijn. 2002. "Women's Labour Market Position and Divorce in the Netherlands: Evaluating Economic Interpretations of the Work Effect", European Journal of Population 18:2: 175--202.

South, Scott J. 1995. "Do you need to shop around?", Journal of Family Issues 16(4): 432--449.

South, Scott J. and Kim Lloyd. 1995. "Spousal alternatives and marital dissolution", American Sociological Review 60(1): 21--35.

Teachman, Jay D. 2002. "Stability across cohorts in divorce risk factors", Demography 39(2): 331--352.

Tzeng, Jessie M. and Robert D. Mare. 1995. "Labor Market and Socioeconomic Effects on Marital Stability", Social Science Research 24: 329--351.

Waite, Linda and Lee A. Lillard. 1991. "Children and marital disruption", American Journal of Sociology 96(4): 930--953. 